\title{
Micronutrient supplementation: when is best and why?*
}

\author{
Mary R. L’Abbé†, Kevin A. Cockell and Nora S. Lee \\ Bureau of Nutritional Sciences, Food Directorate, Health Products and Food Branch, Health Canada, \\ Ottawa, ON K1A 0L2, Canada
}

\begin{abstract}
For many nutrients, a systematic determination of the effects of high intakes over extended periods of time has not been conducted. Governments and scientific bodies have just begun to establish the methodology for, and to conduct, nutrient risk assessments for setting 'tolerable upper levels of intake' (UL) for nutrients. Nutrient risk assessment provides the framework for using available information to evaluate the safety of nutrients when added to foods or when consumed as supplements, in order to minimize the risks from over-consumption. When intakes are inadequate, food fortification may be the appropriate choice for some nutrients, while in other situations, when requirements are markedly higher for some population subgroups than for the general population, supplements may be the most appropriate intervention. The present paper will present some examples of how to use the UL along with food consumption data to assess the appropriateness of food fortification $v$. supplementation strategies and to assess their impact on nutrient intakes of the population. The important steps to be followed when evaluating which approach is best are: (a) establishing need, i.e. assessing the gap between current and desired intakes; (b) assessing safety, i.e. consider the margin of safety between requirement and UL as well as the severity and reversibility of the adverse effect that was used to establish the UL; (c) estimating exposure through statistical modelling, in which population-based estimates of intakes before and after the intervention are compared; (d) monitoring the impact of the intervention to ensure that the desired benefits are achieved and that excessive intakes are minimized. This approach can optimize the public health benefits of food fortification or supplement use while minimizing the risks due to excessive intakes.
\end{abstract}

\section{Micronutrient intakes: Nutrient risk assessment: Tolerable upper levels of intake: Supplementation v. fortification strategies}

When it comes to nutrients, more is not always better. Nevertheless, as consumers learn that the intake of some nutrients at levels above current intakes may provide health benefits beyond their traditional roles in the prevention of nutrient-deficiency diseases and maintenance of body stores, the demand for and interest in fortified foods and supplements increases. Under these situations, there must also be concern about 'How much is too much?' If there is evidence indicating that the diet is not meeting nutrient needs, there are a variety of approaches, each with its own advantages and disadvantages, which can be used to improve intakes. One option is fortification, i.e. changing the food supply by the addition of vitamins and minerals to specific foods or to a range of products. A second option is education. A series of easily understandable messages has to be developed that will influence dietary behaviours and improve the intake of nutrients of concern through better food choices. A third option is the use of supplements. Supplementation may be the best approach when specific population subgroups have a clear and distinct need, but may involve additional costs, and its successful implementation would also require a large education component. Ultimately, some combination of all these approaches may form part of a national strategy to address any gaps that may exist between what is needed and what is consumed. Whatever strategy is adopted, a method is needed to determine whether a proposed action will be effective in meeting a public health objective without jeopardizing the safety of the food supply.

\footnotetext{
Abbreviations: DRI, dietary reference intake; NRA, nutrient risk assessment; NTD, neural-tube birth defects; RDA, recommended dietary allowance; UF, uncertainty factor; UL, tolerable upper intake level.

*Bureau of Nutritional Sciences Publication no. 575.

†Corresponding author: Dr Mary R. L’Abbé, fax +1 613941 6182, email mary_l'abbe@hc-sc.gc.ca
} 


\section{Nutrient risk assessment process}

Until recently, a specific framework for reviewing scientific evidence on health risks associated with high intakes of nutrients did not exist. An ad hoc working group was established in the Food Directorate at Health Canada to develop a systematic approach to the evaluation of such health risks. The Health Protection Branch model of risk determination (Health Protection Branch, 1993), in use at the time for establishing safe intakes of substances such as environmental contaminants and food additives, was adapted for this purpose (L'Abbé et al. 1997). An outline of the four-step nutrient risk assessment (NRA) model is shown in Fig. 1. The steps are hazard identification, hazard characterization, exposure assessment and risk characterization. The main adaptations in making this model an NRA model are described in later sections.

\section{Steps 1 and 2: establishing 'upper (safe) levels' for nutrients}

The following paragraphs briefly outline the NRA process developed and used at Health Canada. The Food and Nutrition Board of the US National Academy of Sciences

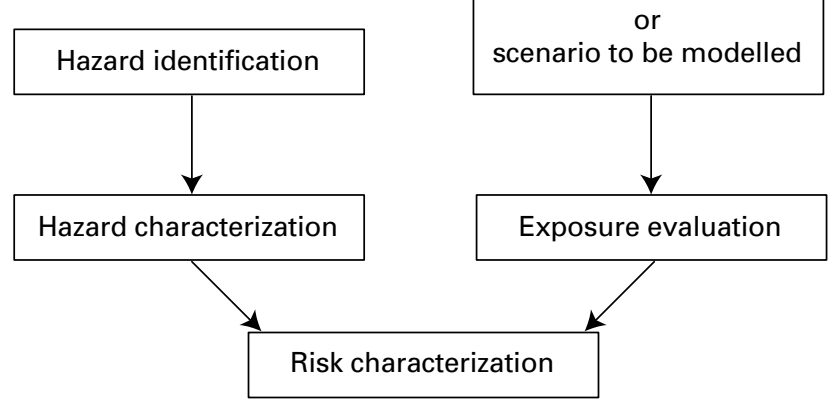

Fig. 1. Outline of the nutrient risk assessment model. The outcome of hazard identification and hazard characterization is the determination of a tolerable upper level of intake. The existing nutrient content of foods is used in the first round of exposure evaluation. Changes in risks associated with a particular fortification or supplementation scenario can then be evaluated by altering the food composition or supplement use data, according to the scenario being evaluated, and redoing the exposure evaluation. This procedure will provide the basis for the risk characterization of the scenario(s) being examined. For details, see p. 414. have developed a similar approach in their NRA. The first two steps of the NRA are used for determining 'tolerable upper levels of intake' (UL; Food and Nutrition Board, $1998 a$; 2002). Several other government agencies and scientific bodies have also begun to establish the methodology for, and to conduct, NRA for setting UL for nutrients. Some of the recent activities in this area are detailed in Table 1. All the evaluations tend to follow the same steps, although with slight variations in the data sets or uncertainty factors (UF) that are used. Once a UL is established, individual jurisdictions can apply it along with appropriate intake data to complete the steps of the NRA.

In the first step, hazard identification, all potential adverse effects of elevated intakes of a particular nutrient, as reported in the literature, are identified. These effects may be either direct effects attributable to the nutrient under consideration, or indirect effects mediated through an interaction with other nutrients, drugs or food components. Identification of population subgroups that are particularly at risk is also done in this step; for example, short-term exposure during critical periods (such as the teratogenic effect of early fetal exposure to excess vitamin A) may be pertinent for some nutrients.

The second stage of NRA is hazard characterization, which is sometimes referred to as dose-response modelling. It involves quantification of the probability of occurrence of the potential adverse health effect(s) identified during hazard identification across a range of nutrient exposure levels. Hazard characterization can sometimes involve statistical modelling to determine the minimum dose level at which the adverse effect is likely to occur (the 'lowest observed adverse effect level' or the highest dose level with no observed adverse effect. In view of the nature of nutrients, the role of absorption, bioavailability, metabolism and excretion must be considered in the dose-response modelling. Such factors could have important effects on the dose of the nutrient that is delivered to the target organ(s) and, consequently, on the probability of an adverse effect in response to any given intake. Interactions with other nutrients, drugs and food components identified during hazard identification are to be considered in this step for the same reasons. In this step an UF is usually applied to the no observed adverse effect level or lowest observed adverse effect level to arrive at the UL for the nutrient. UF are used to address the uncertainties involved in extrapolating from the available data to the general population, including such

Table 1. Upper (safe) levels for nutrients that have been established by various government agencies

\begin{tabular}{|c|c|c|}
\hline Agency & Year & Upper (safe) levels for nutrients \\
\hline EU, Scientific Committee for Food & 1993 & Maximum safe intake level \\
\hline France, CSHPF & 1996 & Safety limits for seven vitamins, three minerals \\
\hline $\begin{array}{l}\text { US National Academy of Sciences } \\
\text { (USA and Canada) }\end{array}$ & 1997; reviews ongoing & $\begin{array}{l}\text { Tolerable upper intake level, one of the dietary reference intake values } \\
\text { established for nutrients }\end{array}$ \\
\hline Canada & 1997 & Nutrient risk assessment methodology; Ca risk assessment parts I and II \\
\hline EU, Scientific Committee for Food & 2000; reviews ongoing & Development of tolerable upper intake levels for a variety of nutrients \\
\hline Nordic countries & 2001 & Safe range of intake \\
\hline WHO & 2002 & Acceptable range of oral intake \\
\hline UK Food Standards Agency & 2002 & Safe upper levels \\
\hline
\end{tabular}

CSHPF, conseil supérieur d'hygiène publique de France. 
issues as interindividual variation in sensitivity, interspecies extrapolation, the use of a lowest observed adverse effect level rather than a no observed adverse effect level, and the suitability of the data sets used, i.e. data obtained from subchronic exposure studies when there is a lack of chronic data (Food and Nutrition Board, 1998a; World Health Organization, 2002). However, when the UL is derived from studies involving the most sensitive group in the population, an UF of 1 may be used (World Health Organization, 2002). Also, the choice of an UF must be made with an awareness that nutrients are required for health, unlike contaminants, and that the application of UF cannot result in an UL below the recommended dietary allowance (RDA).

\section{Steps 3 and 4: exposure evaluation and risk characterization}

Exposure evaluation involves the use of recent dietary survey data that are representative of the usual intakes of the subject population in order to develop nutrient intake or exposure profiles for the total population, as well as for any population subgroups identified as 'at risk' during the hazard identification step. Depending on the purpose of the NRA, current intakes should be documented in addition to potential intakes under a suitable range of fortification, supplementation or even food pattern modification scenarios. To the extent possible, exposure profiles developed should describe distributions of nutrient intake for age-gender groups spanning the population. Exposure evaluations must include all oral sources of the nutrient under assessment, including ingestion in foods (as naturally-occurring nutrients or as food additives or fortificants), from supplements and other over-the-counter drugs and, in the case of mineral nutrients, from water. The data obtained will indicate the proportions of each demographic subgroup falling above or below predetermined intake levels considered relevant for the nutrient and the issue in question.

The information obtained from hazard characterization and exposure evaluation is combined in the final phase of the risk assessment to produce the risk characterisation, a determination of how many of the population will be at risk of a given adverse effect as a result of the scenario being examined. This step involves the determination of the proportion of the population (or population subgroups) that would be estimated to exceed the UL and evaluating the extent of excess intake of the nutrient that is projected to occur. As the nature of the critical adverse effect upon which the UL was established varies for each nutrient, it is not possible to use a simple rule to state how much is too much. This decision will require consideration of a number of factors, such as the severity and reversibility of the adverse effects associated with both deficiency and excess.

NRA can be used to assess the potential risks and benefits associated with a proposed fortification plan to address inadequate intakes in a population, or to evaluate the potential for supplements to address an identified nutritional need, e.g. to meet the increased needs of pregnancy. Achieving a desired public health outcome without exposing the population to unacceptable health hazards is the primary goal of any public health agency. Through NRA, the impact of different fortification or supplement use scenarios on nutrient intake levels and associated public health benefits can be estimated, as can the potential for nutrient-associated adverse effects for each population subgroup. NRA can even be used to assess the risks associated with high levels of exposure that might be created through a fortification error etc. Conducting a NRA in advance is particularly important when evaluating end points for a possible food fortification intervention that may extend into quasi-pharmacological effects, such as the role of folic acid in the reduction of the risk of neural-tube birth defects (NTD). Proposed interventions to address identified nutrient intake shortfalls will require increasing vigilance to avoid excessive intakes, as the evolving basis for nutrient intake recommendations has led to higher intake recommendations, resulting in narrower margins of safety between recommended intakes and UL. The example of folic acid fortification to reduce the risk of NTD will be discussed in greater detail later in the present review.

\section{The changing basis for determining nutrient requirements}

The importance of nutrition in the maintenance of health has been recognized by government agencies for many years. Recommendations for nutrient requirements were first based on the intake levels needed to protect the population from nutrient-deficiency diseases, such as scurvy, rickets, etc. In recent years, as the basis for determining nutrient requirements has evolved, a greater emphasis is being placed on the role that nutrients may play in prevention of chronic and degenerative diseases and on what intakes may be associated with this role. Thus, the term RDA, which is used to define nutrient requirements, has remained essentially the same over the years; what has changed is the definition or criterion that is used to establish the requirement.

In the dietary reference intake (DRI) report for $\mathrm{Ca}$ and related nutrients (Food and Nutrition Board, 1997), the B-vitamins (Food and Nutrition Board, 1998b), antioxidants (Food and Nutrition Board, 2000) and micronutrients (Food and Nutrition Board, 2002), nutrient adequacy is now defined by specific indicators or biomarkers, which can be related to a reduction in the risk of chronic degenerative diseases or disorders. For example, for $\mathrm{Ca}$, maximal $\mathrm{Ca}$ retention was chosen as an indicator of nutritional adequacy, as increased bone mass in early adult life would reduce the risk of fractures secondary to osteopenia or osteoporosis in later years. This information led to defining an adequate intake of $1000-1300 \mathrm{mg} / \mathrm{d}$ for women (Food and Nutrition Board, 1997), which represents an increase from earlier requirement estimates of $700-1100 \mathrm{mg} / \mathrm{d}$ (Health and Welfare Canada, 1990b) and $800-1200 \mathrm{mg} / \mathrm{d}$ (Food and Nutrition Board, 1989).

For some nutrients this changing definition of 'adequacy' has shifted the RDA greatly upwards. For example, in Canada in 1990 the folic acid requirement for women was $170-190 \mu \mathrm{g} / \mathrm{d}$, depending on age (Health and Welfare Canada, 1990b), based on observed dietary intakes and bioavailability in populations without classical folate deficiency. The US RDA of $180 \mu \mathrm{g} / \mathrm{d}$ for women was estimated to provide for liver stores adequate to guard against development of deficiency symptoms during short periods 
of inadequate intake (Food and Nutrition Board, 1989). To address basic nutrient requirements for all adults, the recommendation was increased to $400 \mu \mathrm{g}$ dietary folate equivalents/d in the DRI report in 2001 (Food and Nutrition Board, 1998b). More drastically still, in the same report, a separate recommendation was made that women who could become pregnant should consume $400 \mu \mathrm{g}$ folic acid from supplements or fortified foods over and above the amounts naturally present in their diets, in order to reduce the risk of NTD in their offspring. The total recommended intake for these women is, therefore, approximately $900 \mu \mathrm{g} / \mathrm{d}$, if converted to dietary folate equivalents; an amount almost impossible to obtain on a daily basis from a normal unfortified diet.

\section{Assessing adequacy of population intakes}

Nutritional status of a population can be assessed by the use of several approaches: (a) biomarkers of status (e.g. functional measures of status, measures of nutrient supply to tissues, measures of tissue stores); (b) assessment of nutrient intakes through national food intake surveys; (c) estimates of nutrient intakes through the use of food disappearance data or product sales data. The availability and specificity of indicators of nutrient intake vary greatly among nutrients, and their reliability for assessing nutrient status, in general, decreases when moving from biomarkers to food intake to food disappearance. The appropriateness of different indices of nutritional status along with their equivalence and/or complementarity needs to be examined, since the choice of indicator can have a huge impact on conclusions regarding nutrient adequacy.

Regardless of the end point or the criterion used to establish the requirement for a particular nutrient, adequacy of current intakes is determined by comparing these intakes with the established nutrient requirement for the particular life-stage and gender group. With the development of the latest DRI, the new term 'estimated average requirement' was introduced. The estimated average requirement is defined as 'the average daily nutrient intake level estimated to meet the requirement of half the healthy individuals in a particular life-stage and gender group'. Estimated average requirements were established for all nutrients for which appropriate data were available. According to the uses and implementation report for the DRI, this value is to be used to assess the prevalence of inadequate intakes within a population (Food and Nutrition Board, 2001).

\section{Approaches to addressing nutrient gaps}

\section{Food fortification}

Food fortification is a public health initiative with a long history of being used effectively to remedy nutritional deficiencies that were causing widespread national public health problems. Fortification is also used to improve the nutritional quality of the national food supply to ensure adequate supplies of nutrients for which intakes may be marginal. Inherent in taking a food fortification approach are questions surrounding how to deliver the nutrient to those who need the intervention while avoiding potential adverse effects, such as excessive or imbalanced intakes, in other groups. Other questions involve the choice of an appropriate food vehicle, whether addition is mandatory or voluntary (the latter often requires education for effective implementation).

There are a number of reasons why governments have policies concerning the addition of nutrients to foods. They provide a uniform set of principles, which, when applied, ensure a rational and consistent approach to the addition of nutrients to foods. Food fortification policies can be used to achieve the public health objectives of maintaining and improving the overall nutritional quality of the national food supply and of addressing the nutritional needs of specific population subgroups. Their application can avoid random nutrient addition, which could lead to excessive intakes while not addressing inadequate intakes and may create nutrient imbalances.

Under the Codex general principles for the addition of essential nutrients to foods (Food and Agriculture Organization, 1994), the basic principles for addition of vitamins and minerals to foods are related to specific public health objectives. To meet the challenges posed by the widening definition of nutrient requirements, food fortification policies need to be developed that recognise and address these broader public health objectives. Food fortification approaches could include specific initiatives that would:

1. improve the nutritional quality of the food supply to meet the widened definition of nutrient adequacy, as defined, for example, by the recent DRI, rather than simply to prevent deficiencies;

2. increase the nutrient density of foods or provide foods targeted to particular groups or subgroups (i.e. a wider variety of foods for infants, the elderly, etc.);

3 . increase the variety of food products that are good sources of particular nutrients.

There are other potential reasons for fortifying foods, which may increase the availability of nutrients in the food supply or provide other benefits to the food industry or consumers, but which can be considered to have little public health benefit. Examples of such reasons could include fortifying foods to provide an alternative to vitamin and mineral supplements in the form of a food, using food fortification specifically as a marketing feature, using food fortification to encourage food industry innovation or to enhance trade opportunities.

Early experiences with vitamin D fortification in Canada illustrate many of the fundamental principles of utilizing food fortification to address a national public health problem (Health and Welfare Canada, 1990a). During the 1940s and 1950s, any un-standardised food sold in Canada could be fortified with vitamin $\mathrm{D}$ at a minimum level of $100 \mu \mathrm{g}$ and a maximum of $200 \mu \mathrm{g}$, based on a reasonable daily intake. A wide range of vitamin D-fortified products came onto the market, including fruit drinks, biscuits and cocoa mixes. However, a survey of children in Ontario in 1963 showed that many infants and young children were receiving over $500 \mu \mathrm{g} / \mathrm{d}$, two-thirds of which came from supplements, and older children ( $\geq 8$ years) could easily be exposed to $1000 \mu \mathrm{g} / \mathrm{d}$. At the same time, rickets continued to be a problem in children. The appearance of a number of 
cases of idiopathic hypercalcaemia of infancy, mostly in the UK in the mid 1950 s to early 1960 s, which was thought to be related to high intakes of vitamin $\mathrm{D}$, drew additional attention to this situation. When the addition of vitamin D to foods was restricted in the UK in an effort to reduce the risk, the rate of idiopathic hypercalcaemia of infancy declined. In 1964 action was taken to stop the addition of vitamin D to un-standardised foods in Canada. This action was part of broader government regulations that restricted the addition of vitamins, minerals and amino acids to only those foods identified in the regulations. The restrictions on vitamin D addition resulted in an increase in rickets. However, the addition of vitamin D to fluid milk in the late 1960s to early 1970 s dramatically reduced the prevalence of rickets in Canada. In 1975 this fortification was made mandatory to ensure its universal application, leading to the virtual elimination of childhood rickets in Canada. These experiences highlight one of the fundamental principles of food fortification that had been overlooked earlier, i.e. the selection of an appropriate vehicle to reach the target population. It is noteworthy that in the $1990 \mathrm{~s}$ cases of childhood rickets reappeared in Canada; these cases, however, were mostly associated with the consumption by young children of plant-based beverages, without vitamin $\mathrm{D}$, in place of milk.

\section{Supplements}

The use of supplements as an approach to improving nutrient intakes is clearly the one most easily utilised on an individual basis, but has rarely been used as a population intervention approach. In theory, if all women, for example, would take a daily $\mathrm{Ca}$ supplement, this approach would be the most efficacious low-risk means of improving their $\mathrm{Ca}$ intakes. In practice, however, this approach is limited by the fact that communication of recommendations is generally incomplete and supplement use requires ongoing individual choice, making it unreliable. Also, supplements are less likely than a fortification programme to reach poorer populations. Berner et al. (2001) found that supplement use is more prevalent among population groups with higher education and higher incomes.

Experience with folic acid supplements for prevention of NTD illustrates some of these difficulties. In a Canadian study of pregnant women attending a genetics clinic at an Ottawa paediatric hospital ( $n 342$ ), $81 \%$ were aware of folic acid and $78 \%$ were currently taking at least $0.4 \mathrm{mg} / \mathrm{d}$ (the recommended amount for prevention of NTD). It should be pointed out that these were a group of women who were in stable relationships, employed and three times more likely than the general population to have completed post-secondary education. However, only $26 \%$ had begun supplementation early enough in pregnancy to actually reduce the risk of NTD (Dawson et al. 2001).

\section{Education programmes}

An effective supplementation programme requires an effective education effort. An intense media campaign targeting women in The Netherlands was able to increase folic acid supplement use from $<1 \%$ in 1994 to $52 \%$ in
1998 (Bekkers \& Eskes, 1999). On the other hand, in a study in Colorado in which women who had a NTD-affected pregnancy in 1996 or 1997 ( $n$ 21) were contacted in 1998, only one who had a subsequent pregnancy had followed the recommendation to consume a daily folic acid supplement starting at least 1 month before conception (Callender et al. 2001). In another Colorado study $53 \%$ of women with NTD-affected pregnancies did not know about the recommendation to take $4 \mathrm{mg}$ folic acid/d for NTD recurrence protection (Rinsky-Eng \& Miller, 2002). In a recent Canadian study, based on a questionnaire given to $>1200$ women in 1999-2000, $70 \%$ of the respondents were aware of the preventative role of folic acid against NTD, yet only $25 \%$ had taken the recommended dose of supplement during the periconception period (Morin et al. 2002). Thus, with education programmes, even with effective message awareness, difficulties are often experienced in changing actual behaviours. Studies have shown, however, that in the case of the folic acid supplement message, where physicians or other key health care professionals counsel their patients using correct advice, compliance increases markedly (Pastuszak et al. 1999). This finding suggests that incorporation of key health messages such as folic acid supplement use into, for example, the annual health check, could improve effectiveness of supplement recommendations. Education programmes are basically the only way to deliberately effect changes in food consumption patterns, at least in a Western democratic country. Food guides are the primary tools for conveying messages about appropriate food consumption patterns so that most of the population obtain a healthy diet adequate in all nutrients. It has been customary in the past to seek to promote improved food intakes to ensure nutrient adequacy as a first step, following that promotion step with the addition of nutrients to foods if the standard food supply tended to be inadequate in a nutrient. Supplementation recommendations have generally been a last resort of public health policy makers. With the new DRI that are intended for use by Canadians and Americans, it appears that more reliance on supplementation and fortification is inevitable to help the population achieve the RDA.

\section{Using nutrient risk assessment methodology to assess benefits as well as risks}

Having established that a nutrient intake shortfall exists in a substantial proportion of the population, an assessment using the NRA model is advisable as part of the process of deciding among the various options for improving intake. In the third NRA step, exposure evaluation, exposure levels that could be expected to occur under a range of possible fortification, supplement use or education scenarios, should be determined, in addition to documenting current exposure levels. These scenarios should represent a range of options that are designed to achieve the desired health benefit. As described earlier, to the extent possible, exposure profiles should describe distributions of exposure for each identified population group of interest. They should include data on the proportion of the population that is exposed, and the level of exposure among those exposed, by suitable age and gender groups where possible. 
For nutrients for which there are safety concerns or established UL, exposure evaluations must include several important factors. These factors are: (a) the margin of safety between the requirement level and the UL; (b) the severity and reversibility of the adverse effect; (c) the exposure characteristics of the population (i.e. the proportion of the population expected to exceed the UL) or the impact on specific groups (e.g. vegetarians or the elderly). In evaluating population exposures the effects of permitting fortification of a specific food product and/or food groups (i.e. food vehicles) $v$. unrestricted addition of a nutrient to the food supply should be determined. NRA must also consider the total food supply as a whole, rather than simply assessing the effects of fortification of individual foods in isolation. For example, for $\mathrm{Ca}$, which has a narrow margin of safety between requirement and UL, fortification of a single or a few food products would be unlikely to increase intakes above the UL, while unrestricted addition of $\mathrm{Ca}$ to many foods may readily do so, particularly in some demographic groups, such as adolescent males, who may consume large amounts of many food products (Johnson-Down et al. 2003).

\section{Monitoring}

Monitoring the impact of fortification or supplementation programmes, following their introduction, should be conducted to permit an evaluation of their success and allow for further 'tuning' of programmes in response to the findings. Later surveillance that reveals changing food habits may also signal a need for changes to programmes. Several examples of studies conducted to assess the impact of mandatory folic acid fortification of flour in Canada, introduced in 1998, are included in the case study mentioned later.

\section{Case study: folic acid fortification of flour in Canada}

The US Food and Drug Administration (1996) and Health Canada (McCourt et al. 1998) conducted risk evaluations in order to determine whether food fortification would be an appropriate means of increasing the folate intakes of women of childbearing age, and hence reducing the rates of NTD. In Canada exposure evaluations, which involved the simulation of flour and pasta fortification at various levels using available Canadian dietary survey data, indicated that flour would have to be fortified with folic acid at $350 \mu \mathrm{g} / 100 \mathrm{~g}$, and pasta at a corresponding level, for women to reach a mean total intake of $400 \mu \mathrm{g} / \mathrm{d}$ (Table 2; McCourt et al. 1998). This approach would still result in $<50 \%$ of women aged 18-34 years reaching $400 \mu \mathrm{g}$ folate/d, while a marked percentage of men aged 18-34 years (11) would have intakes exceeding the UL (Table 3). Given that the objective was for all women who could become pregnant to obtain $400 \mu \mathrm{g}$ folic acid in addition to naturally-occurring dietary folate on a daily basis, these exposure evaluations suggested that the desired public health objective could not be achieved in the target population unless fortification was at such a level that it would be considered unsafe for some other population subgroups. A lower level of fortification $(150 \mu \mathrm{g} / 100 \mathrm{~g}$ flour $)$ was then chosen; at this level, modelling showed that the
Table 2. Folic acid fortification of flour: modelling the effects of different levels of folic acid fortification on mean folic acid intakes ( $\mu \mathrm{g} /$ day) of Canadian women (adapted from McCourt et al. 1998)

\begin{tabular}{lcccc}
\hline $\begin{array}{l}\text { Scenario } \\
(\mu \mathrm{g} / 100 \mathrm{~g})\end{array}$ & $\begin{array}{l}18-34 \\
\text { years }\end{array}$ & $\begin{array}{l}35-49 \\
\text { years }\end{array}$ & $\begin{array}{l}50-64 \\
\text { years }\end{array}$ & $\begin{array}{l}65-74 \\
\text { years }\end{array}$ \\
\hline Baseline & 161 & 175 & 189 & 182 \\
40 & 175 & 190 & 195 & 188 \\
70 & 205 & 218 & 215 & 207 \\
140 & 274 & 285 & 260 & 251 \\
350 & 481 & 484 & 396 & 384 \\
\hline
\end{tabular}

Table 3. Folic acid fortification of flour: modelling the effects of folic acid fortification of flour (at $350 \mu \mathrm{g} / 100 \mathrm{~g}$ flour) on folic acid intakes $(\mu \mathrm{g} / \mathrm{d})$ of young Canadian men and women (adapted from McCourt et al. 1998)

\begin{tabular}{|c|c|c|c|c|c|}
\hline \multirow[b]{2}{*}{ Gender } & \multicolumn{3}{|c|}{ Folic acid intakes $(\mu \mathrm{g} / \mathrm{d})$} & \multirow{2}{*}{\multicolumn{2}{|c|}{$\begin{array}{c}\begin{array}{c}\text { Percentage with } \\
\text { folate intake } \\
75 \% \%^{*} \quad>1000 \mu \mathrm{g} / \mathrm{d}\end{array} \\
\end{array}$}} \\
\hline & Age (years) & $25 \% *$ & Median & & \\
\hline $\mathrm{F}$ & $18-34$ & 314 & 386 & 465 & - \\
\hline M & $18-34$ & 435 & 582 & 760 & 11 \\
\hline $\mathrm{F}$ & $35-49$ & 300 & 370 & 477 & - \\
\hline M & $35-49$ & 384 & 480 & 579 & 4 \\
\hline
\end{tabular}

*25th and 75 th percentiles of intake.

expected mean intakes for women of childbearing age would be $250-285 \mu \mathrm{g}$ total folate/d (McCourt et al. 1998). It was decided that, since a fortification programme that would achieve the intakes known to be effective in reducing NTD risk could not be implemented, women who could become pregnant would continue to be advised to take a supplement of $400 \mu \mathrm{g}$ folic acid/d.

Since the introduction in 1998 of mandatory folate fortification of flour in Canada, erythrocyte folate levels in young women (mean age 31.8 years) have increased from $<500 \mathrm{nmol} / 1$ ( $\left.\begin{array}{lll}n & 8 & 408\end{array}\right)$, before its introduction, to $700-800 \mathrm{nmol} / \mathrm{l}$ (n 30 061; Ray et al. 2002). Rates of NTD in some Canadian provinces have also declined substantially (Gucciardi et al. 2002; Persad et al. 2002). For example, in Nova Scotia, a province with historically a relatively high rate of NTD, rates have dropped from approximately 2.5 per 1000 to approximately one per 1000, or less, post-fortification (Table 4). This reduction could in part be due to supplementation, although the level of the contribution of supplements is not clear. The effectiveness of folic acid fortification of flour and enriched pasta in increasing blood folate levels and reducing NTD rates has been greater than originally expected. This outcome has not been fully explained but could relate to one or two possible factors. The level of folic acid added to flour is probably higher than that prescribed by the government regulations, as manufacturers tend to add 'overages' to ensure that the minimum amount stipulated in the regulations is met. In a study of folic acid-fortified foods in the USA analysed folate levels in many foods 
Table 4. Yearly incidence of open neural-tube birth defects (NTD; per $1000^{*}$ ) in Nova Scotia Canada, before folic acid supplementation (1991-4), after supplementation but before folic acid fortification of flour and pasta (1995-7) and after mandatory fortification of flour and pasta (1998-2000) $\ddagger$ (adapted from Persad et al. 2002)

\begin{tabular}{lccc}
\hline Year & Open NTD $\dagger$ & Spinabifida & Anencephaly \\
\hline Pre-supplementation & & & \\
$\quad 1991$ & 2.51 & 1.34 & 1.09 \\
1992 & 2.48 & 1.49 & 0.83 \\
1993 & 2.56 & 1.37 & 1.11 \\
1994 & 2.64 & 1.59 & 0.97 \\
$\begin{array}{l}\text { Post supplementation and } \\
\text { pre-fortification }\end{array}$ & & & \\
1995 & 2.11 & 1.28 & 0.73 \\
1996 & 3.54 & 2.33 & 0.93 \\
1997 & 2.17 & 1.19 & 0.79 \\
Post fortification & & & \\
1998 & 1.43 & 0.82 & 0.51 \\
1999 & 1.11 & 0.52 & 0.31 \\
2000 & 0.94 & 0.52 & 0.31 \\
\hline
\end{tabular}

* Live births, still births and pregnancies terminated because of fetal anomalies.

†Includes spinabifida, anencephaly and encephaloceles.

†Fortification permitted January 1998, addition made mandatory November 1998.

were 1.5- to 2-fold higher than the required amounts (Rader et al. 2000). Similar 'overages' were found in a small survey of flour sold in Canada ( $R$ Peace, personal communication). Another factor may be the nature of the exposure. Rather than a single bolus once daily, as with supplement use, intake from food would tend to be associated with a more constantly elevated serum level, which could perhaps affect the metabolic efficiency with which folate is used in tissues.

In conclusion, these examples illustrate the usefulness of the NRA process and many of the considerations involved when contemplating a supplementation or fortification programme. The NRA approach provides a useful framework for evaluating the expected public health benefits or risks associated with advocating supplementation or the addition of nutrients to foods, as the aim is to design a programme to optimize nutrient intakes while minimizing risks of excessive intakes.

\section{References}

Bekkers RL \& Eskes TK (1999) Periconceptional folic acid intake in Nijmegen, Netherlands. Lancet 353, 292.

Berner LA, Clydesdale FM \& Douglass JS (2001) Fortification contributed greatly to vitamin and mineral intakes in the United States, 1989-1991. Journal of Nutrition 131, 2177-2183.

Callender ES, Rickard R, Miller L \& Rinsky-Eng J (2001) Knowledge and use of folic acid supplementation: a study of Colorado women whose pregnancies were affected by a fetal neural tube defect. Clinical and Investigative Medicine 24, 124-128.

Dawson LE, Pham B \& Hunter AG (2001) Low rate of adequate folic acid supplementation in well-educated women of high socioeconomic status attending a genetics clinic. Canadian Medical Association Journal 164, 1149-1150.
Food and Agriculture Organization (1994) Codex Alimentarius. vol. 4, Foods for Special Dietary Uses (Including Foods for Infants and Children). Joint Food Standards Programme, 2nd ed. Rome: Codex Alimentarius Commission.

Food and Drug Administration (1996) Food Labelling: Health Claims and Label Statements; Folate and Neural Tube Defects; Proposed Rule and Final Rule. Federal Register 21: CFR 101. Washington, DC: National Academy Press.

Food and Nutrition Board (1989) Recommended Dietary Allowances, 10th ed. Washington, DC: National Academy Press.

Food and Nutrition Board (1997) Dietary Reference Intakes for Calcium, Phosphorus, Magnesium, Vitamin D and Fluoride. Washington, DC: National Academy Press.

Food and Nutrition Board (1998a) Dietary Reference Intakes: A Risk Assessment Model for Establishing Upper Intake Levels for Nutrients. Washington, DC: National Academy Press.

Food and Nutrition Board (1998b) Dietary Reference Intakes for Thiamin, Riboflavin, Niacin, Vitamin $B_{6}$, Folate, Vitamin $B_{12}$, Pantothenic Acid, Biotin and Choline. Washington, DC: National Academy Press.

Food and Nutrition Board (2000) Dietary Reference Intakes for Vitamin C, Vitamin E, Selenium and Carotenoids. Washington, DC: National Academy Press.

Food and Nutrition Board (2001) Dietary Reference Intakes. Applications in Dietary Assessment. Washington, DC: National Academy Press.

Food and Nutrition Board (2002) Dietary Reference Intakes for Vitamin A, Vitamin K, Arsenic, Boron, Chromium, Copper, Iodine, Iron, Manganese, Molybdenum, Nickel, Silicon, Vanadium, and Zinc. Washington, DC: National Academy Press.

Gucciardi E, Pietrusiak MA, Reynolds DL \& Rouleau J (2002) Incidence of neural tube defects in Ontario, 1986-1999. Canadian Medical Association Journal 167, 237-240.

Health Protection Branch (1993) Health Risk Determination: The Challenge of Health Protection. Ottawa, Ont.: Supply and Services Canada.

Health and Welfare Canada (1990a) Mandatory Addition of Vitamins A and D to Milk - Background Paper. Ottawa, Ont.: Nutrition Evaluation Division, Food Directorate, Health Protection Branch.

Health and Welfare Canada (1990b) Nutrition Recommendations The Report of the Scientific Review Committee. Ottawa, Ont.: Minister of Supply and Services Canada.

Johnson-Down L, L'Abbé MR, Lee NS \& Gray-Donald K (2003) Food habits of Canadians: Modelling scenarios for fortifying the Canadian food supply with calcium. Journal of Nutrition 133, (In the Press).

L'Abbé MR, Cockell KA, Dubois S \& Ross WH (1997) Report on Calcium Risk Assessment. Parts I and II, Hazard Identification and Hazard Characterization. Ottawa, Ont.: Food Directorate, Health Protection Branch, Health Canada.

McCourt C, Turner L, Lee N \& Junkins B (1998) Risk Evaluation of Fortification Measures to Respond to the Evidence for a Protective Effect of Folate Against Neural Tube Defects. Ottawa, Ont.: Health Canada.

Morin P, De Wals P, St-Cyr-Tribble D, Niyonsenga T \& Payette H (2002) Pregnancy planning: a determinant of folic acid supplements use for the primary prevention of neural tube defects. Canadian Journal of Public Health 93, 259-263.

Pastuszak A, Bhatia D, Okotore B \& Koren G (1999) Preconception counseling and women's compliance with folic acid supplementation. Canadian Family Physician 45, 2053-2057.

Persad VL, Van den Hof MC, Dube JM \& Zimmer P (2002) Incidence of open neural tube defects in Nova Scotia after folic acid fortification. Canadian Medical Association Journal 167, $241-245$. 
Rader JI, Weaver CM \& Angyal G (2000) Total folate in enriched cereal-grain products in the United States following fortification. Food Chemistry 70, 275-289.

Ray JG, Vermeulen MJ, Boss SC \& Cole DE (2002) Increased red cell folate concentrations in women of reproductive age after Canadian folic acid food fortification. Epidemiology 13, 238-240.
Rinsky-Eng J \& Miller L (2002) Knowledge, use, and education regarding folic acid supplementation: continuation study of women in Colorado who had a pregnancy affected by a neural tube defect. Teratology 66, Suppl. 1, S29-S31.

World Health Organization (2002)Principles and Methods for the Assessment of Risk from Essential Trace Elements. Environmental Health Criteria no. 228. Geneva: WHO. 